\title{
Risk, Welfare, Education and Youth
}

\author{
Jason L. Powell \\ Faculty of Health \& Life Sciences, Coventry University, Priory Street, CV1 5FB, \\ Coventry, United Kingdom \\ E-mail address: j.powell@coventry.ac.uk , jasonpwll3@gmail.com
}

\section{ABSTRACT}

This paper the concept of risk as applied to an understandin relationship between social welfare and youth in the United Kingdo on the sociological work of Ulrich Beck (1992) in order to exam ne changes modern society have led to what has been coined the 'risk society'. The pap en ass is historical narratives of social welfare which positioned younger individuals in socruy. The $/$ moves attention to examining neo-liberalism in contemporary times as a key eature of the 'risk society' and the recasting of the state, welfare agents and younger people. In articular, th paper observes the rise of managerialism and consumer narratives that are central neo-liberal sm and management of social welfare yet are indicative of risk. The paper concludes by ing f an interface between risk and a critical sociology of youth.

Keywords: Risk; Education; Youth; Theory; Neo-1 b ralisn

\section{INTRODUCTION}

This paper ana ses $\mathrm{t}$ oncept 'risk', which both as a theoretical tool and dimension of modern socie $y$, is slowly ing developed within the sociology of education (Powell, 2013). Notwit stand o this, the concept of risk and the meaning and implications associated with it, have ben ful explored in relation to youth despite on or two exceptions (cf. Cartmel and Fú o, 1997). Risk is shrouded in historical and contemporary political debate about wI 'role d/ responsibility' is it for 'youth' in society - does it reside with the stz or th individyal? Or some combination of the state, the family and the individual youn he historical responsibility for the protection and security of youth has graduals hifted towards that of the state, famously epitomised in the United Kingdom by William B cridge's "cradle to the grave" welfare protectionism of younger people (Leonard 1997). In contemporary times, however, this approach has changed with the move from state protectionism to individual responsibility. The shift from protection of the individual to selfprotection by the individual has been claimed to be illustrative of the phenomena of the 'risk society' (Beck 1992). Such a society has been defined in terms of the erosion of traditional values (Giddens 1991) and the desire to allocate accountability and responsibility for personal or social actions (Beck 1992) Ideas associated with the 'risk society' have, it might be argued, become part of the organizing ground of how we define and organise the 'personal' and 'social spaces' in which to be problematized as 'youth problem' (Epstein, 1998). In what 
follows the paper explore this idea both for understanding agency in youth, and for further developing the aims and objectives of a critical sociology of youth (Furlong, 1997).

The paper begins by examining some of the arguments put forward by Ulrich Beck (1992) and the relevance of these for understanding how changes in modern society have shaped the welfare identities of younger people. To illustrate this, the paper reviews the historical rise and consolidation of social welfare in the United Kingdom. The paper assesses how risk has impinged on changing forms and modern practices of the 'welfare state'. From this, the paper traces the welfare transformations to what can be defined as the 'risk society' (Beck 1992) and the impact of this on identity in youth formations and key areas such os the relationship of younger people to the state (Cartmel and Furlong, 1997; Epstein,

The paper then moves to assessing neo-liberalism as a key feature of th 'risk socie and the re-positioning of younger people as 'consumers' and welfare age ts as anager The paper then evaluates the implications of neo-liberal social policy fo younger $\mathrm{p}$ le nd professional practices by using the 'risk' framework derived from th work Ulrio Beck (1992).

\section{TRANSFORMING AGE}

As a starting point we should note the dramati has underpinned definitions of age identities. In th way in which ageing identities were transformed in the second world war (Powell 2013). The kry develop

change in the ins, itutional structure that context it if important to highlight the
two dec des following the ending of two dec des following the ending of in advanced capitalist societies, youth social and economic institutions associated with the welfare state suc a cucation, training and work (Powell 2013). These became crucial in shaning the ominant discourse around which youth was framed, and the identities asso ate vithin a d across the lifecourse (Epstein, 1998). A supporting theme was the re-ring of the lifecourse into distinctive stages associated with education, work and retire th thanom to retirement becoming an important element in the development of a v identit) parate from that associated with youth, work and paid employment (Phillip on

On this last Ne ment, $\mathrm{L}$. debate in the 1940s and 1950s focused on the need to escape the injustice an deprivation ed in the economic depression of the 1930s (Frith, 1984). Hence, what s bee lesaribed by one historian of social policy (Rodney Lowe) as the role of the welfare in moy g society to a higher ethical ground. Lowe (1993: 21) suggests in fact th welh stat was seen as being able to: 'elevate society by institutionalising a deer er sen of com anity and mutual care'.

ov erase link between youth and images of poverty (Hall et al. 1978). The possibility of transform $\mathrm{ge}$, through more secure provision of education and training, was a significant component of the post-war social contract. Education for younger people was viewed, first, as a fair exchange for work and income. Second, in rhetorical terms, as a measure of the way in which younger people were now protected from the hazards of social inequality. Third, as part of the intergenerational contract and indicative of the close ties maintained between family groups, younger and older (Arber and Attias-Donfut 2000).

If the welfare state created -or set out to create- a new identity for youth, it was the transformation in welfare from the 1980s onwards which posed a new challenge to the status 
and identity of younger people. The crisis in youth that took hold from this period reflected, to a significant degree, the loosening of the institutional supports underpinning the life course. Younger people were themselves the creation of modernity, reflecting the achievements of industrialism, improved public education and the growth of social welfare (Powell and Edwards, 2002). The steady growth in the proportion of younger people in the UK population was, up until the beginning of the 1980s, largely contained within the dual institutions of education and work.

These, along with the ties maintained between generations, created a social, economic and moral space within which growing numbers of younger people could be channellod and contained. In this regard, education and work was predominantly a state of affair 1or you $\mathrm{rr}$ people may be seen as accurate in at least two senses: first, in terms of the wa tat resour were distributed; second, in relation to the identities and forms of surveillence cod. For period of 20 years or more, moving younger people into the zone of york from cati on, held at bay the underlying issue of securing a place and identit for a g vit $A$ the framework of an advanced capitalist society. The meaning of your wa nporari at least, constructed out of a modernist vision where education and w were ved "natural" points in the human life cycle.

The unravelling of these arrangements can be trace to a st three types of crisis affecting the management of youth in the last quarte or he twen. century: economic, social and cultural. The economic dimension has be hell-rehearsed with successive crises from the mid-1970s onwards undermining, first, goal of frll employment (and hence destabilising retirement), and, second, the fiscal ba of the w/fare state (accelerated with the onset of a privatisation from the 1980s emwards) (H adwards, 2002).

These aspects led to the development acial sphere of what to paraphrase Carroll Estes et al (2001) refers to as the 'crisis cons uct' an 'crisis management' of youth, with youth now socially constructed as a "nroblem' or society (Cartmel and Furlong, 1997). At its most extreme, demographic char ge $n$ itself $n$ w viewed as a source of the economic crisis, notably in respect of the ap ant $j$ balance between 'productive' and 'non-productive' sectors in the economy (I ma itself came to be viewer slaying ontributory role in the alienation of younger people in western society.

The sense $g^{2}$ un wase a the nature of demographic change itself chimed in with a wider discours about wider do copments accompanying the transition from a modern to a postmodern arld ( urad 1992). Uncertainties about the benefits of aging are certainly nothing new. $\mathrm{h}$ onist a lounts of the place of younger people in past societies have tended to emp the $p^{1}$ ive naracter of economic relief, and the marginalisation of those lacking gaip ul em loyment all et al. 1982). Both aspects may be found as significant elements in pres da the assault on minimum wage a ' 'st fears of 'too few workers' over an 'excess' of pensioners (Vincent 1999). But these hist continuities are given added emphasis in a postmodern age.

Arguably, younger people have the most to lose given the restructuring of relationships associated with postmodernity. The extension of individualization may, to take one example, be perceived as highly threatening to identity in the beginning phase of the life-course. As Giddens (1991) argues, modern life raises at least two possibilities: the promise of a multiplicity of identities on the one side, and the danger of ontological insecurity on the other. Similarly, Biggs (1993) suggests that in response to these circumstances, individual actors will attempt to find socially constructed spaces that lend some form of predictability to 
everyday relationships. Yet in a postmodern world such spaces may be increasingly difficult to locate.

\section{FROM WELFARE STATE TO RISK SOCIETY}

From the 1980s onwards, the crisis affecting youh illustrated the way that the problem of social marginality among the young had been contained rather than resolved in the postwar period. Moreover, what a postmodern setting did have to offer -namely the idaal of consumption replacing that of production- seemed only to further marginalise gr ups su younger people. Bauman, for example, writes of the accelerating emancipation capital fro labour producing a situation where: 'instead of engaging the rest of socinty he role producers, capital tends to engage them in the role of consumers' (Baur an 1992: TAis transformation in fact reflects a more general shift from the public $\mathrm{p}^{\mathrm{r}}$ ision gracte ac of what Lash and Urry (1987) refer to as 'organized capitalis mor flexible arrangements running though the period of 'disorganised capital $\mathrm{m}$ '.

This development has served to change once again the tion of wh to be an younger person. In the conditions of advanced modernit grow up moves from being a collective to an individual experience and responsibilit..... notion aging society (with social obligations) becomes secondary to the emp asis on the way which families and younger individuals handle the demands associated th populatich aging.

This new development may be seen as a cha teristic of a society where the 'social production of risk' runs alongside that asso ianted with al production of wealth' (Beck 1992). As already argued, improved life exp may itself be viewed as a consequence of the social transformations associated with mo lerr La. Beck (1992: 21) defines the nature of risk as a 'systematic way of dealino with ho ards and insecurities induced and introduced by modernization itself' (autho s $\mathrm{e}_{\mathrm{A}}$ hasis). 'f course, younger people have been everpresent in human history. But aray arase Beck, in the past these could be seen as personal rather than societal traged (or uevermus). The impact of younger people was limited both by their lack of de graphic ence compared to older people and, crucially, by the relatively superficial nat of the ca egory of 'problem delinquent' or 'anti-social young person' (Jeffersop 200 ). changes consequent upon modernisation transformed both these elements, with vouth beco ing a new and socially recognised risk.

But in 'ne $y$ Reck's thesis about the nature of risk society are three main developments . Ing thro gh an understanding of youth. First, the globalisation of youth is increas recos ed- 1 societies (poor as well as rich) are undergoing similar population tran orma ons (alb with notable exceptions such as those in countries devastated by the AIL vir crowing up thus becomes simultaneously both a biographical event and one sharea th different cultures and societies across the globe.

Sec youth experiences are themselves hugely (and increasingly) diverse. Under the guise of the welfare state, growing up was compressed into a fairly limited range of institutions and identities (notably in respect of income and lifestyles). Youth in the postwelfare society, however, has substantially expanded in respect of social opportunities as well as new inequalities and divisions (Cartmel and Furlong, 1997; Vincent 1995).

Third, youth is also being changed by what Beck (1992) describes as the era of reflexive modernization. This may be conceived in terms of how individuals and the lay public exert control and influence on the shape and character of modernity. At its core, Beck's (1992: 10) approach suggests the thesis that:'...the more societies are modernised, the more agents 
(subjects) acquire the ability to reflect upon the social conditions of their existence and to change them in that way'. For younger people, this highlights the move from conditions of structured oppression towards the possibility of new, consumer-based lifestyles (Fornas and Bolin, 1995). On the other hand, this almost certainly goes hand-in-hand with the marginalisation of significant groups of younger people, trapped in the contradiction between decreasing personal incomes (incomes and savings) and the steady withdrawal of support from the state for their future pension provision (Powell, 2001).

These developments confirm the seriousness of the challenge facing younger people. In reality in terms of their social position, the young have moved into a new 'mone of indeterminacy' which is marginal to work and welfare (Epstein, 1998). Yoy iger p y experience the world truly as though they were riding (as Giddens 1991,28 ey sses it in description of high modernity) a 'juggernaut': '...it is not just that more r les ontinuo and profound processes of change occur; rather, change does not consis ently cont eit er to human expectation, or to human control'. This may seem a relativel gbstra descri on of the crisis which younger people may experience but it rather accur ely eys the cality of what may happen to younger people in situations of rapid chang

\section{RISK, SELF-AUTONOMIZATION AND MANAOIG OLD
A POST-WELFARE SOCIETY?}

Youth is itself becoming a more social, reflex and man aged process, notably in the relationships between the individual, the tate and public as well as private services; this involves the "political domain' 1 with this, processes and relationships in the management of youth are decided by poli cal at aties (neo-liberalism) that are bound up with ideological and philosophical quest ns of self-governance and autonomy. Neoliberalism considers that a we are ciety $\mathrm{m}$ st reflect only the interplay of social and political structures forged out elf- snonsibj, ity and consumerism (Leonard 1997; Powell 2001). In recent years, yg er 'vic as antonomous consumers derive their 'education', individually and collect $1 \mathrm{y}$, from a $\mathrm{ge}$ of social policies, institutions and sites, so that the organisation of educe on olves man et forces, schools, state and families.

The neo-libe existential conc pts such as see csponsibility, self-governance and self-care that are said to facilitate hur acti (Leonard 1997). The regulation of personal conduct has shifted from being presente a respo ibility of the state to the responsibility of micro-level social actors such a 'ofess l experts' and 'younger people' as 'consumers' (Epstein, 1998). The imp' catio are pro, and. As Nikolas Rose (1996: 59-60) has pointed out:

vantaged individual has come to be seen as potentially and ideally an active ag in the fabrication of their own existence. Those 'excluded' from the benefits of a life choice and self-fulfilment are no longer merely the passive support of a set of social determinations: they are people whose self-responsibility aspirations have been deformed by the dependency culture, whose efforts at self-advancement have been frustrated... they are to be assisted as active citizens [through] programmes of empowerment to enable them to assume their rightful place as the self-actualizing and demanding subjects of an 'advanced' liberal democracy'.

Here neo-liberalism attempts to define the social policy domain to interpret valid human needs. Under neo-liberalism, the state re-invents itself and its welfare subjects based upon 
minimal intervention and regulation via a rolling program of privatization, deregulation, and contraction of welfare services (Estes et al. 2001).

Within the 'mixed economy of welfare', there has been the social construction of a market- orientated, consumer-based approach to the delivery of education and the role of younger people as consumers. As Powell (2013) claims the neo-liberal state is being reorganized to include retention of a strong centre to formulate policy but the dissemination of responsibility for policy implementation to managerial regimes. As Gordon (1991: 36) points out:

'The fulfilment of the liberal idea ... is a recasting of the interface between th and society to one of market order. It becomes the ambition of neo-liberalis $y$ to impli individuals as players into the market game administered by actors'.

Management as an administrative power (cf. Habermas 1992) consolidating neo-liberalism by adding 'choice' and reducing 'sks' d 'pr ems' associated with younger people in education system in UK: a me e rom t state as education provider for schooling subjects" to a manageria' one on nonit ring" and "assessment" in neo-liberal market economy (Fornas and Boli, 95 ).

The movement away from a traditional local auth ity of imprementing state education to an actuarial and privatised role of "manage is a fea ogf the risk society "teaching professions" have had their knowledge base transform 4 from philanthropic 'teacher' to 'manager' of budgets, audits and accou ting systems ((Fornas and Bolin, 1995). In emergent neo-liberal managerial regimes, jud nent is i creasingly bound up with managerial imperatives concerning risk assessment, objectives, purchasing and resource control ((Fornas and Bolin, 1995). devolution of managerial responsibilities is intended to empower younger individuals an to on professional autonomy by having such c managers internalize budgetary disci nes and translate social policy imperatives (Leonard 1997).

These imperatives have a r ajor imp.ct upon social policy and youth. Such neoliberal reforms were abou cas you people as consumers in a market place to be managed by managerial egimes (H 11 2001; cf. Habermas 1987). Education management as an administrative or are also 'K-assessors' and 'enforcers' of the mixed education economy, a discorrs that es younger people who engage in 'education market', on the contradictory ad "risky" gh of being simultaneously 'consumers' and potential 'problems' in 'vidua (Biggs and Powell 2001; Powell and Biggs 2000).

Furlong Cartm (1997) argues that neo-liberalism consistently equates selfrespons ${ }^{-1 \cdot i t y}$ wh "reed $m$, with younger people presented as active agents in a consumer marl et. $\mathrm{H}_{\mathrm{b}}$ ever, a sons associated with class, gender and ethnic position may still leave man poc vounger people highly vulnerable - despite the neo-liberal vision of the 'respo, Te consumer'. Gendered inequalities may be especially important in this scenario. As Nanc) acer suggests:

'Participants in the 'masculine' subsystem are positioned as right-bearing beneficiaries and purchasing consumers of services. Participants in the 'feminine' subsystem, on the other hand, are positioned as dependent clients' (1987: 113). 


\section{CONCLUSION}

By constituting risk as a centrally defining motif of "late modernity" this paper contributes to new perspective for 'critical sociology of youth'. This paper has raised questions about the historical and contemporary understanding of social forces that are an important qualification in understanding the shifting discourses associated with the transformation from the welfare state to the risk society. Younger people it might be argued are affected by two major changes in respect of access to support on the one side, and the construction of identity on the other. On the one side, there is the creation of 'no cara rones where community supports may disintegrate in the face of inadequate services nd ben. On the other side, there may equally be the emergence of 'No Identity Zones' se reflect the absence of spaces in which to construct a viable identity for younger neop. Phillips and Biggs 1999).

The argument here is that marginality is now being experien $\mathrm{d} \mathrm{h}, \mathrm{cW}$ and mewhat distinctive way by younger people. Marginality, for much of e post-th verig, could be reclaimed through identities constructed out of an emergin a ensus reg ang education and social welfare (Fornas and Bolin, 1995). The collaps a this o ensus has exposed once again the vulnerable status of younger people. But therabil io not just about the material experience of deprivation, it also reaches i to the texture of day-to-day living. For more affluent groups, a temporary solution seems to ave been found in the the promotion of new lifestyles. The social and existential vacuum $m$ this sug gests reinforces the sense of uncertainty about the identity of younger paople (Epsu oso). The great advantage of the loosening of 'welfarist' notions of age lie possibility of an alternative social and political construction of youth beginning t er which might move beyond welfare structures based on assumptions of dapendend This hew politics would present a challenge to the constraints placed upon leco e devel oment for younger people and opportunities for meaningful agency witho sing sight of the social threats posed by new forms of risk and insecurity.

\section{References}

[1] Arber S ttias- nfut C., 2000. The Myth of Generational Conflict. London: Routledge

[2] Buth Z., 19 Vimations of Postmodernity. London: Routledge \& Kegan Paul. [3] ck 1092 Kisk Society. London: Sage.

[4] Bes 1980. Flexible Life Scheduling. New York: Praeger.

[5] Biggs \$, 1999. The Mature Imagination. Milton Keynes: OUP.

[6] Biggs S., 2000. "Elder Abuse and Surveillance: The Rationalities and Technologies of Community Care", Journal of Contemporary Health, 4: 43-49.

[7] Biggs S., Powell J. L., 2001. "A Foucauldian Analysis of Old Age and the Power of Social Welfare", Journal of Aging \& Social Policy 12: 93-111.

[8] Delanty G., 1999. Social Science: Beyond Constructivism, Sage: London. 
[9] Department of Health, 1989. Caring for People: Community Care in the next Decade and Beyond, Cmnd. 849. London: HMSO.

[10] Department of Health, 1994. NHS Hospital Activity Statistics: England 1983-94Statistical Bulletin. London: Department of Health.

[11] Estes C., Associates, 2001. Social Policy and Aging. Thousand Oaks: Sage Books.

[12] Epstein J., 1998 Youth Culture: Identity in a Postmodern World, Blackwell.

[13] Frith S., 1984 The Sociology of Youth, Causeway.

[14] Fornas J., Bolin G. 1995 Youth Culture in Late Modernity, Sage.

[15] Furlong A., Cartmel F. (1997) Young People and Social Change, Routled

[16] Fraser N., 1987. "Women, welfare and the politics of need interpreta 40. ', $H$. Journal of Feminist Philosophy, 2: 102-121.

[17] Giddens A., 1991. The Consequences of Modernity. Oxford:

[18] Gilleard C., Higgs P., 2000. Cultures of Ageing: self, citi- and the bo London: Prentice-Hall.

[19] Gordon C. 1991. "Governmental rationality: an in contion", $\mathrm{P}_{\mathbf{1}} \mathbf{5 1}$ in G. Burchell, C. Gordon and P. Miller (Eds.) The Foucault Effed Studies in Gove nmentality, Chicago: Chicago University Press.

[20] Habermas J., 1992. Postmetaphysical Thinking, nbridge polity press.

[21] Leonard P., 1997. Postmodern Welfare don: Sage.

[22] Lowe R., 1993. The Welfare State in Brt in sincy 945. London: Macmillan.

[23] Minkler M., Estes C. (eds.) Critica Gerontology: Perspectives from Political and Moral Economy. Ne York Baywoo

[24] Otway H., B. Wynne 99. Communication: Paradigm and Paradox, Risk Analysis, 9: 141-

[25] Phillipson C. 98. K qstructing Old Age, London: Sage Books.

[26] Phillipson C., Biggs S. 19 Population Ageing: critical gerontology and the sociolo al tra ion". Education and Ageing, 14: 159-170.

[27] Powell J. L 001. "7 Meorizing Gerontology: The Case of Old Age, Professional Power 114 cial Po the United Kingdom”, Journal of Aging \& Identity, 6: 117-135.

[20, owe L B Biggs S., 2000. "Managing Old Age: The Disciplinary Web of Power, reilramu and Normalisation", Journal of Aging and Identity, 5: 3-13.

[29] Powy Y., (2013) Social Gerontology, New York: Nova Science

[30] Rose N., 1996. “Governing advanced liberal democracies”. Pp.37-64 in Barry, A, Osborne, T., and Rose, N. (Eds.) Foucault and Political Reason, Chicago: Chicago University Press.

[31] Stearns P., 1977. Old Age in European Society: The Cast of France. London: Croom Helm.

[32] Townsend P., Wedderburn D., 1965. The Aged in the Welfare State. London: Bell. 
[33] Vincent J., 1995. Inequality of Old Age. London: UCL Press.

[34] Vincent J., 1999. Politics, Power and Old Age. Buckingham: Open University Press.

[35] Wynne B., 1987. Risk Management and Hazardous Waste. Berlin: Springer.

( Received 30 November 2013; accepted 06 December 2013 )

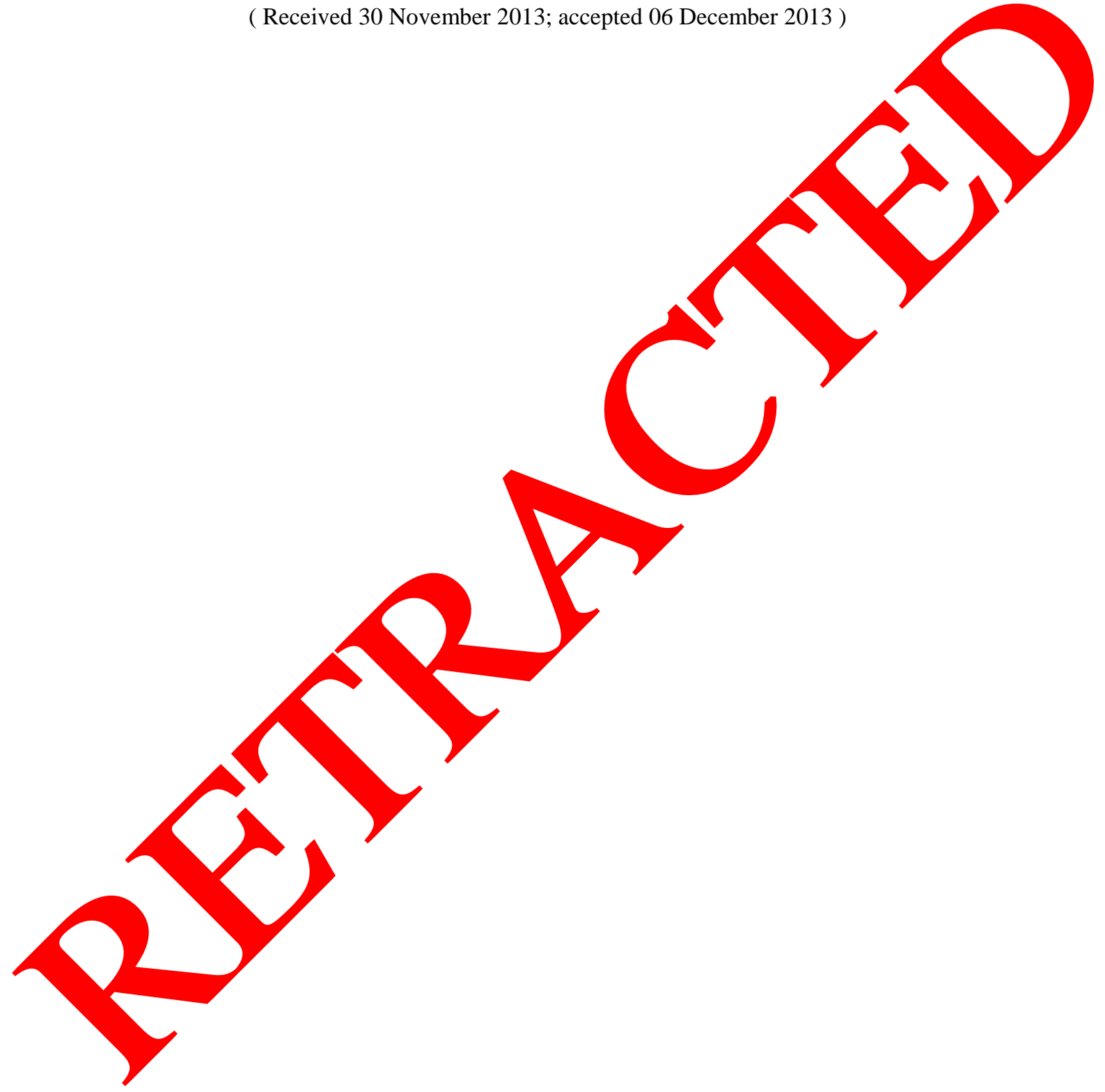

